\title{
Tribological Performance of Phosphonium Ionic Liquids as Additives in Lithium Lubricating Grease
}

\author{
Zeyun Wang *, Jun Chang and Chao Cai \\ School of Chemistry and Chemical Engineering, Ningxia University, Yinchuan 750021, China; \\ cj_changjun@163.com (J.C.); cchlxl@nxu.edu.cn (C.C.) \\ * Correspondence: 1234wangzeyun@163.com; Tel.: +86-182-9558-3191
}

Received: 8 January 2018; Accepted: 20 February 2018; Published: 27 February 2018

\begin{abstract}
Three oil-miscible phosphonium ionic liquids with different structures were synthesized and used as additives for a Poly Alpha Olefin 10 (PAO 10) lithium lubricating grease. Different from other additives, the ionic liquids participated in saponification and were trapped in the entanglement network formed by the thickener. The effects of the ionic liquids on the rheological properties of lithium lubricating grease were characterized through a small-amplitude oscillatory shear (SAOS) measurement. The tribological performances of the lubricating greases were determined on a four-ball friction tester. The addition of phosphonium ionic liquids caused a decrease in the storage $\left(G^{\prime}\right)$ and loss $\left(G^{\prime \prime}\right)$ modulus of lubricating grease. However, the ionic liquids were found to be effective lubricant additives for improving the friction-reducing and antiwear properties of PAO 10 lithium lubricating grease.
\end{abstract}

Keywords: lithium lubricating grease; ionic liquid; additive; rheology

\section{Introduction}

Lubricating grease, consisting of a thickener dispersed in mineral or synthetic oil, is usually used in gears, bearings, and other mechanical moving parts [1], where it acts as a lubricant and sealing agent. Due to its semisolid character, grease posseses the advantages of both oil and solid lubricant. However, the nature and rheological properties of greases are essentially different from those of oil and solid lubricant. In lubricating grease, an entanglement network formed by the thickener traps the oil and confers the appropriate rheological property to the grease [2]. Under certain loading conditions, the grease usually maintains its solid form and does not flow. However, when the load reaches the grease's "critical stress", it begins to flow like a lubricating oil [3]. Studying the rheological properties of lubricating greases is important not only under working conditions but also under static conditions. This is because the rheological properties of lubricating greases are responsible for preventing a loss of lubrication [4].

Recently, ionic liquids (ILs) have been shown to exhibit immense potential for lubricant applications because of their reduced volatility, nonflammability, and thermal stability [5]. Several papers have been published on the use of different types of ILs as lubricants, lubricant additives, or base oils to prepare lubricating grease [6-11]. However, from the aspect of engine applications, using a small amount of ILs as an additive seems to be an economical option due to the high cost of ILs [12]. Over the last few years, the corrosion and low miscibility of ILs in non-polar oils restrict their application as additives for most base oils. Recently, some kinds of high miscibility and noncorrosive ILs, such as phosphonium-based ILs, were developed. Qu et al. first investigated the oil-miscible ionic liquid (trihexyltetradecylphosphoniumbis(2-ethylhexyl) phosphate) as a potential antiwear lubricant additive. In a synthetic base oil, this ionic liquid demonstrated superior antiscuffing and antiwear properties [13]. Westerholt et al. developed an economic halide-free route to synthesize oil-miscible 
ammonium- and phosphonium-based ionic liquids. The prepared ionic liquids showed remarkable tribological performance as a base oil or an additive [14]. Up to now, little work has been carried out on using phosphonium-based ILs as grease additives. ILs have been proved to be effective additives in greases $[15,16]$. However, the ILs were usually added to the greases after the greases were already prepared. This method can cause the grease system to be instable. Therefore, our group considered mixing a certain amount of oil-miscible IL in base oil and using the oil-IL blends to prepare lubricating grease. In this process, the oil-miscible ILs were not physically mixed with the grease but participated in saponification. The ILs were trapped in the entanglement network formed by the thickener.

In this paper, we synthesized and characterized phosphonium-based ILs with different anions and cations and dissolved 5 wt \% ILs in Poly Alpha Olefin 10 (PAO 10) base oil. Then, the oil-IL blends were used as base stock to prepare lithium greases. The physical and rheological properties of the lithium greases were investigated. The tribological performances of the lubricating greases were determined in the form of friction coefficient and wear volume on a four-ball friction tester.

\section{Experimental Section}

\subsection{Synthesis and Characterization of the Ionic Liquids}

Trioctyltetradecylphosphoniumbis(2-ethylhexyl) phosphate ([P $\left.\left.\mathrm{P}_{88814}\right][\mathrm{DEHP}]\right)$, trioctyl $\left(3^{\prime}-\mathrm{O}, \mathrm{O}^{\prime}-\right.$ diethylphosphinylpropyl)phosphonium bis(2-ethylhexyl) phosphate ([P $888 \mathrm{p}][\mathrm{DEHP}])$, and trioctyltetradecylphosphonium 1,4-bis(2-ethylhexyl) sulfosuccinate ([P $\left.\left.{ }_{88814}\right][\mathrm{AOT}]\right)$ are synthesized in this work. Their structures are shown in Figure 1.

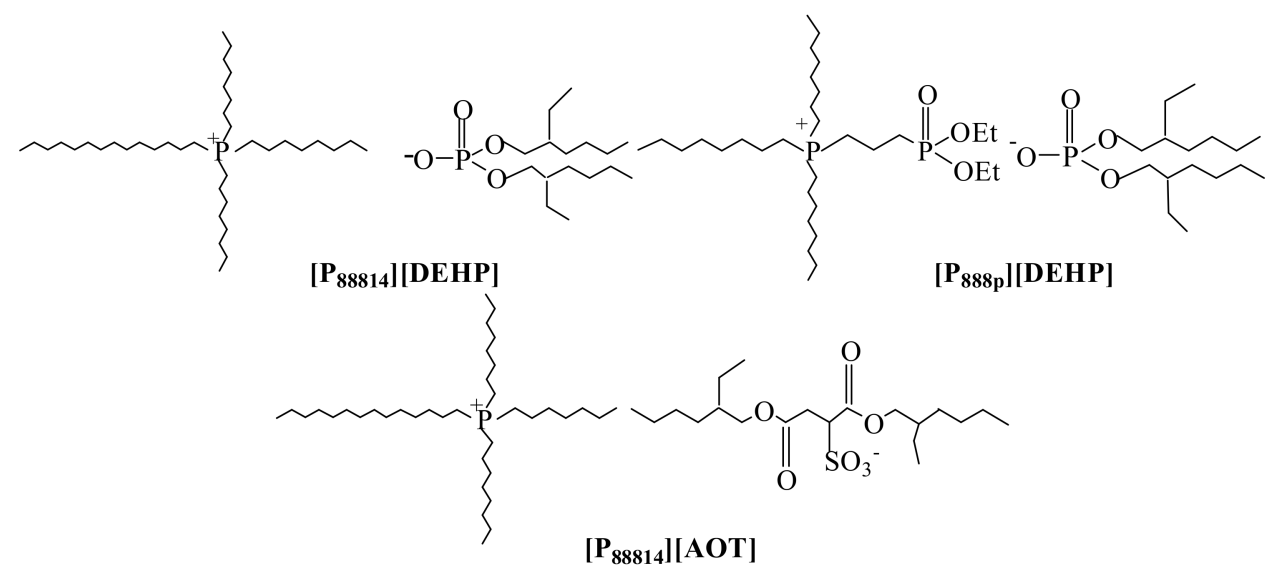

Figure 1. Structures of the ionic liquids (ILs).

$\left[\mathrm{P}_{88814}\right][\mathrm{DEHP}]$ and $\left[\mathrm{P}_{88814}\right][\mathrm{AOT}]$ were synthesized mainly according to the literature reported by $\mathrm{Qu}$ and co-workers [13]. The first step is to synthesize $\left[\mathrm{P}_{88814}\right] \mathrm{Br}$ by stirring a mixture of trioctylphosphine and 1-bromotetradecane at $140{ }^{\circ} \mathrm{C}$ under nitrogen for $24 \mathrm{~h}$. The $\left[\mathrm{P}_{88810}\right]$ Bris then desolved in hexane and the bromine anion is exchanged by bis(2-ethylhexyl) phosphate in the presence of $\mathrm{NaOH}$ ([P $\left.\left.\mathrm{P}_{8814}\right][\mathrm{DEHP}]\right)$ or the sodium 1,4-bis(2-ethylhexyl) sulfosuccinate ([P $\left.\left.\mathrm{P}_{8814}\right][\mathrm{AOT}]\right)$. In order to synthesize $\left[\mathrm{P}_{888 \mathrm{p}}\right][\mathrm{DEHP}], 3^{\prime}-\mathrm{O}, \mathrm{O}^{\prime}$-diethylphosphinylpropyl was initially synthesized by mixing triethyl phosphite and 1,3-dibromopropane with a molar ratio of 2:1 in solvent methylbenzene at $130{ }^{\circ} \mathrm{C}$ for $8 \mathrm{~h}$. Then, middle distillates were collected under vacuum distillation [17]. The cation precursor $\left[\mathrm{P}_{888 \mathrm{p}}\right] \mathrm{Br}$ was prepared by mixing trioctylphosphine and $3^{\prime}-O, \mathrm{O}^{\prime}$-diethylphosphinylpropyl at $140{ }^{\circ} \mathrm{C}$ for $48 \mathrm{~h}$. In a subsequent step, the bromine anion is exchanged by bis(2-ethylhexyl) phosphate in the presence of $\mathrm{NaOH}$.

Thermogravimetric analysis (TGA) was used to characterize the thermal stabilities of the ILs at a $10{ }^{\circ} \mathrm{C} / \mathrm{min}$ heating rate in air from room temperature to $600^{\circ} \mathrm{C}$. Figure 2 shows the TGA curves of the ionic liquids. The onset decomposition temperatures of the ionic liquids were determined by the 
intersection of the tangent and the baseline at the maximum slope of the TGA curves. The kinematic viscosities of ILs were measured at 40 and $100{ }^{\circ} \mathrm{C}$. The typical physical properties of the synthesized ILs are presented in Table 1.

\subsection{Preparation of the Lithium Greases}

The ILs were added into PAO10 with the mass ratio of $5 \mathrm{wt} \%$ and then fully stirred until the ILs were completely dissolved in PAO 10. The formed oil-IL blends were transparent and homogeneous. The lithium greases were prepared following the patent CN103146466A. A certain amount of 12-hydroxystearic acid and sebacic acid was added to a $40 \mathrm{wt} \%$ oil-IL blend heated to $110^{\circ} \mathrm{C}$. When the two fatty acids completely dissolved, the lithium hydroxide aqueous solution was added to conduct a saponification reaction. Then, the mixture was heated to $150{ }^{\circ} \mathrm{C}$ to evaporate the water. When the dehydration was complete, the mixture was heated to $210{ }^{\circ} \mathrm{C}$ and kept at this temperature for $10 \mathrm{~min}$. Finally, the mixture was cooled to room temperature. Lithium grease was obtained by grinding the mixture on a three-roller mill three times.

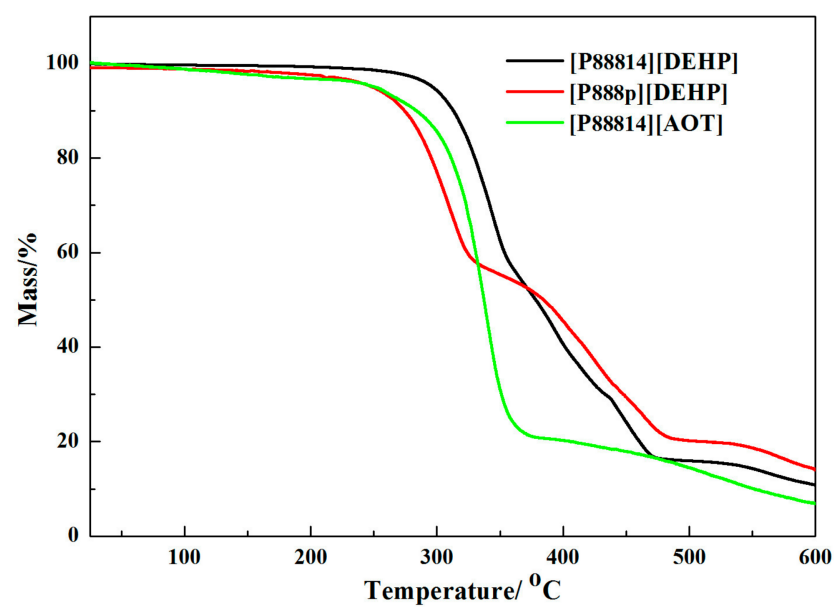

Figure 2. Thermogravimetric analysis (TGA) curves of the ionic liquids.

Table 1. Decomposition Temperature, Density, and Kinematic Viscosity of the ILs.

\begin{tabular}{ccccc}
\hline & $\begin{array}{c}\text { Onset Decomposition } \\
\text { Temperature }\left({ }^{\circ} \mathbf{C}\right)\end{array}$ & Density $\left(\mathbf{g} / \mathbf{m L}, \mathbf{2 5}{ }^{\circ} \mathbf{C}\right)$ & \multicolumn{2}{c}{ Kinematic Viscosity (cSt) } \\
\cline { 4 - 5 } & 225 & $0.83 \pm 0.03$ & $70.1 \pm 0.5$ & $10.4 \pm 0.7$ \\
\hline PAO 10 & 310 & $0.94 \pm 0.05$ & $803 \pm 3$ & $93.7 \pm 1$ \\
{$\left[\mathrm{P}_{88814}\right][\mathrm{DEHP}]$} & 273 & $0.93 \pm 0.02$ & $4586 \pm 2$ & $218 \pm 3$ \\
{$\left[\mathrm{P}_{888 \mathrm{p}}\right][\mathrm{DEHP}]$} & 273 & $0.92 \pm 0.03$ & $664 \pm 2$ & $55.4 \pm 0.9$ \\
{$\left[\mathrm{P}_{88814}\right][\mathrm{AOT}]$} & & &
\end{tabular}

\subsection{Characterization of the Lithium Greases}

The dropping points of the lithium greases were measured using a BF-22 dropping point tester (North Dallan Analytical Instrument Company, Dalian, China). The penetrations were measured using a SYP4100 lubricating grease cone penetrometer (Shanghai Yangde Petroleum Instrument, Shanghai, China). Copper strip tests were carried out to evaluate the corrosion properties of the lithium greases according to the standard GB/T7326-87 method.

The rheological properties of the lithium greases were probed in a controlled-stress rheometryrheoscope using a plate-plate geometry (30 $\mathrm{mm}$ diameter, $1 \mathrm{~mm}$ gap). Small amplitude oscillatory shear (SAOS) measurements (ThermoHaake, Karlsruhe, Germany), inside the linear viscoelasticity region, were performed in a frequency range between 0.1 and $100 \mathrm{rad} / \mathrm{s}$ at $25^{\circ} \mathrm{C}$. 
The linear viscoelasticity region of each sample was determined by a stress sweep test at a frequency of $1 \mathrm{~Hz}$.

The lubrication properties of the lithium greases were evaluated on a four-ball tribotester (Jinan Yihua Tribology Testing Technology Company, Jinan, China). All of the tribotests were conducted at $75{ }^{\circ} \mathrm{C}$ under a normal load of $392 \mathrm{~N}$ (3.42 GPa hertzianpressure) and a rotating speed of $1450 \mathrm{rpm}$ for $1 \mathrm{~h}$. The tribological tests were repeated two times for all lubricating greases. The friction coefficients were recorded automatically by a computer linked to the four-ball tester. The wear scar diameters of the lower balls were measured by an optical microscope (Shanghai Optical Instrument Factory, Shanghai, China) with an accuracy of $\pm 0.01 \mathrm{~mm}$. The wear volumes of the balls were measured using a MicroXAM-3D surface mapping microscope profilometer (KLA-Tencor, Milpitas, CA, USA). The maximum non-seizure loads ( $P_{\mathrm{B}}$ values) tests of the lithium greases were conducted according to Chinese national standard GBT 3142-1982. The measurement conditions were room temperature, $1450 \mathrm{rpm}$, and $10 \mathrm{~s}$.

A JEM-5600LV scanning electron microscope (SEM, JEOL, Tokyo, Japan) was used to examine the morphology of the worn surfaces on the balls. Energy-dispersive X-ray spectroscopy (EDS, JEOL) and PHI-5702 muti-functional X-ray photoelectron spectroscopy (XPS, Physical Electronics, Chanhassen, MN, USA) were used to study the composition of the surface film.

\section{Results and Discussion}

\subsection{Physical Properties of the Lithium Greases}

The physical properties of the lithium greases are presented in Table 2. Among the prepared greases, the $\left[\mathrm{P}_{88814}\right][\mathrm{DEHP}]$ grease showed a higher dropping point than the PAO 10 grease, and the $\left[\mathrm{P}_{888 \mathrm{p}}\right][\mathrm{DEHP}]$ grease and the $\left[\mathrm{P}_{88814}\right][\mathrm{AOT}]$ grease showed a lower dropping point than the PAO 10 grease, indicating that the cation and anion structures of the ILs have effects on the lubricating greases' colloidal structures. From Table 2, it is found that, similar to the PAO 10 grease, the lithium greases prepared using oil-IL blends are also noncorrosive to copper.

Table 2. Physical properties of the prepared greases.

\begin{tabular}{ccccc}
\hline Lubricating Greases & Poly Alpha Olefin 10 & [P $\left._{\mathbf{8 8 8 1 4}}\right][\mathrm{DEHP}]$ & [P $\left._{\mathbf{8 8 8 p}}\right][\mathrm{DEHP}]$ & [P $\left._{\mathbf{8 8 8 1 4}}\right][\mathrm{AOT}]$ \\
\hline Dropping point $\left({ }^{\circ} \mathrm{C}\right)$ & $334 \pm 1$ & $355 \pm 5$ & $295 \pm 1$ & $213 \pm 3$ \\
Penetration $(1 / 4 \mathrm{~mm})$ & $73 \pm 1$ & $78 \pm 1$ & $75 \pm 1$ & $69 \pm 1$ \\
Copper corrosion & $1 \mathrm{a}$ & $1 \mathrm{a}$ & $1 \mathrm{a}$ & $1 \mathrm{a}$ \\
$\left(100^{\circ} \mathrm{C}, 24 \mathrm{~h}\right)$ & & & \\
\hline
\end{tabular}

\subsection{Rheological Properties}

SAOS measurements were used to investigate the influences of ionic liquids on the microstructural network of the greases. Figure 3 shows the evolution of the storage $\left(G^{\prime}\right)$ and loss $\left(G^{\prime \prime}\right)$ modulus and loss tangent $\left(\tan \delta=G^{\prime \prime} / G^{\prime}\right)$ with frequency, within the linear viscoelasticity range at $25^{\circ} \mathrm{C}$. As can be observed in Figure 3a, $G^{\prime}$ is higher than $G^{\prime \prime}$ over the whole frequency range. Nevertheless, the $G^{\prime}$ and $G^{\prime \prime}$ of PAO10 grease is higher than those of the $\left[\mathrm{P}_{88814}\right][\mathrm{DEHP}]$ and $\left[\mathrm{P}_{88814}\right][\mathrm{AOT}]$ greases but similar to the $\left[\mathrm{P}_{888 \mathrm{p}}\right][\mathrm{DEHP}]$ grease. These results indicated that the addition of $\left[\mathrm{P}_{88814}\right][\mathrm{DEHP}]$ and $\left[\mathrm{P}_{88814}\right][$ AOT] brought about deterioration of the grease's microstructural network stability, but the addition of $\left[\mathrm{P}_{888 \mathrm{p}}\right][\mathrm{DEHP}]$ had little impact on the microstructural network stability. Besides this, the addition of ILs not only affected the values of $G^{\prime}$ and $G^{\prime \prime}$ but also the loss tangent. As is shown in Figure $3 b$, the addition of $\left[\mathrm{P}_{888 \mathrm{p}}\right][\mathrm{DEHP}]$ and $\left[\mathrm{P}_{88814}\right][\mathrm{AOT}]$ caused an increase in the relative elastic characteristics of the lubricating grease. However, the addition of $\left[\mathrm{P}_{88814}\right][\mathrm{DEHP}]$ caused the relative elastic characteristics of the lubricating grease to decrease [1]. 


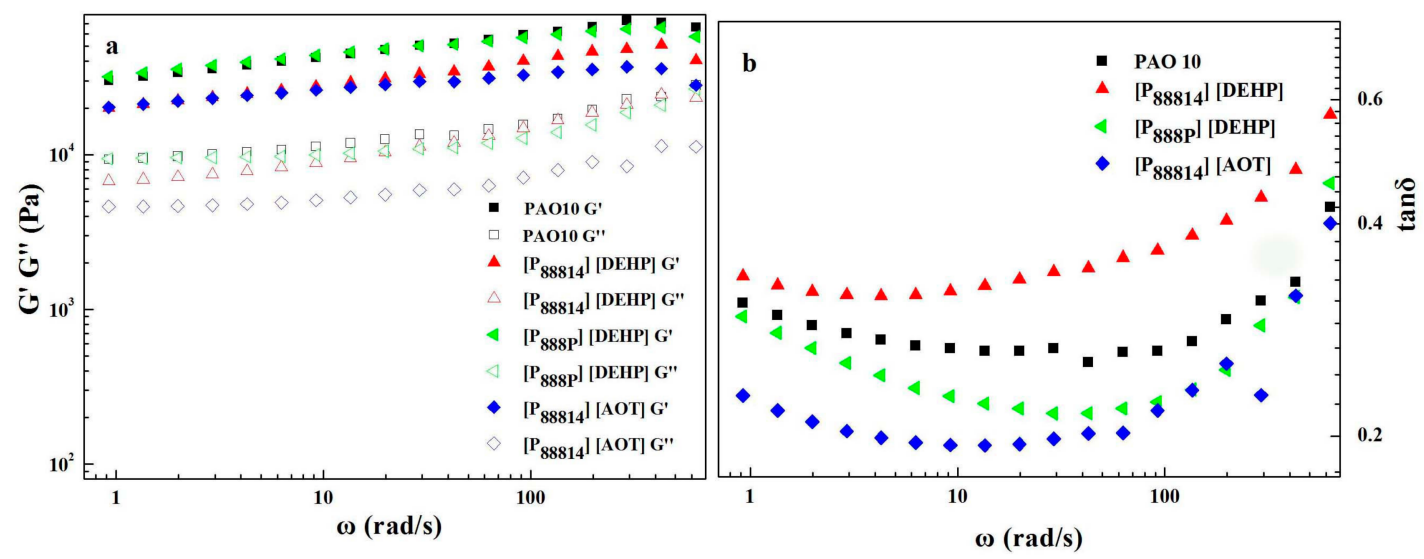

Figure 3. The evolution of the storage $\left(G^{\prime}\right)$ and loss $\left(G^{\prime \prime}\right)$ modulus (a) and loss tangent with frequency (b), within the linear viscoelasticity range at $25^{\circ} \mathrm{C}$, for lithium greases.

\subsection{Tribological Properties}

The tribological performances in terms of friction and wear behavior of the lubricating greases are shown in Figure 4. It is seen that the PAO 10 lubricating grease exhibits a high and unstable friction coefficient and the wear scar diameter is about $0.76 \mathrm{~mm}$. However, after the addition of [ $\mathrm{P}_{88814}$ [DEHP] and $\left[\mathrm{P}_{888 \mathrm{p}}\right][\mathrm{DEHP}]$, the friction coefficient decreased to about 0.05 and stayed stable during the whole sliding process. The wear scar diameter, especially the wear volume, also significantly decreased. Compared with the traditional extreme pressure antiwear additive zincdialkyldithiophosphate (ZDDP), the $\left[\mathrm{P}_{88814}\right][\mathrm{DEHP}]$ and $\left[\mathrm{P}_{888 \mathrm{p}}\right][\mathrm{DEHP}]$ greases exhibited a lower friction coefficient and wear volume. The addition of $\left[\mathrm{P}_{88814}\right][\mathrm{AOT}]$ improved the friction-reduction and antiwear performance of the lubricating grease. Compared with ZDDP, the friction coefficient of $\left[\mathrm{P}_{88814}\right][\mathrm{AOT}]$ is similar to that of ZDDP. However, the wear scar diameter and wear volume of $\left[\mathrm{P}_{88814}\right][\mathrm{AOT}]$ are larger than those of ZDDP.
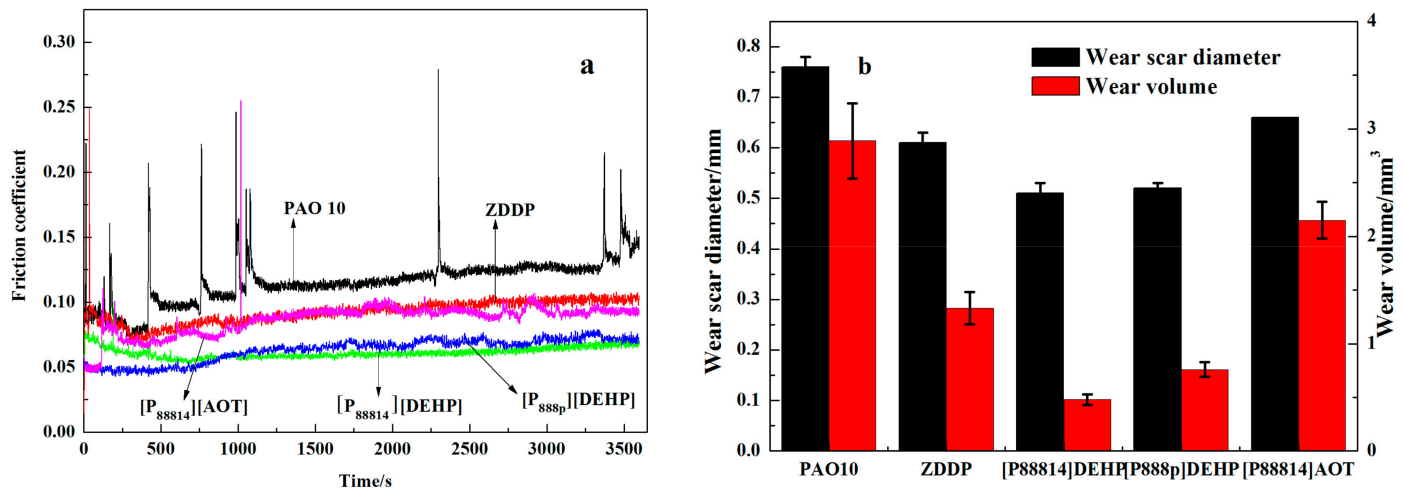

Figure 4. Evolution of friction coefficient with time (a) and wear volume (b) for the lubricating greases (load, $392 \mathrm{~N}$; rotating speed, $1450 \mathrm{rpm}$; temperature, $75{ }^{\circ} \mathrm{C}$; test duration, $1 \mathrm{~h}$ ).

Figure 5 shows the $P_{\mathrm{B}}$ values of the lubricating greases. As is shown in Figure 4, after the addition of phosphonium-based ILs, the $P_{\mathrm{B}}$ values were significantly improved and the $P_{\mathrm{B}}$ values were larger than those of ZDDP, indicating that the ILs exhibited good extreme pressure performances. 


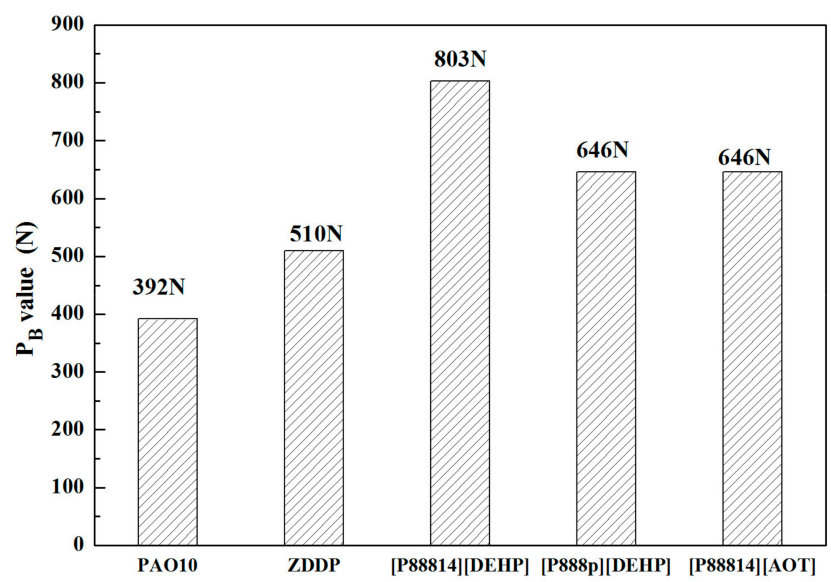

Figure 5. Maximum non-seizure load ( $P_{\mathrm{B}}$ values) for the lubricating greases (rotating speed, $1450 \mathrm{rpm}$; test duration, $10 \mathrm{~s})$.

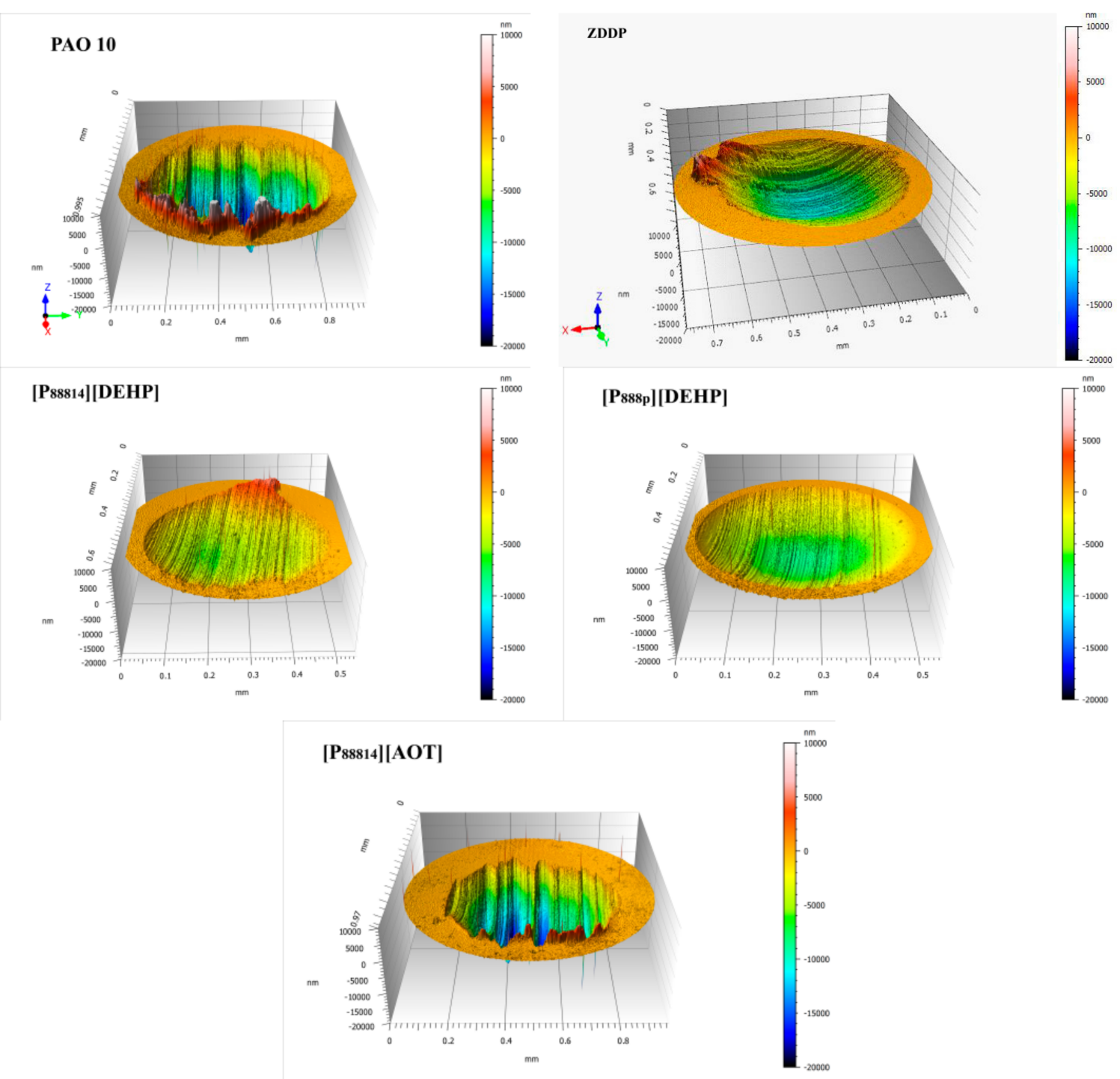

Figure 6. Three-dimensional (3D) images of wear scars lubricated with the lubricating greases. 


\subsection{Surface Analysis}

Figure 6 gives the three-dimensional morphology of the wear scars lubricated with the lubricating greases. It is obviously seen that the wear scar lubricated with the PAO 10 lubricating grease is large and deep. However, the wear scars lubricated with the $\left[\mathrm{P}_{88814}\right][\mathrm{DEHP}]$ and $\left[\mathrm{P}_{888 \mathrm{p}}\right][\mathrm{DEHP}]$ lubricating greases are very shallow. The wear scars lubricated with ZDDP and [ $\left.\mathrm{P}_{88814}\right][\mathrm{AOT}]$ lubricating grease are deeper than those of the $\left[\mathrm{P}_{88814}\right][\mathrm{DEHP}]$ and $\left[\mathrm{P}_{888 \mathrm{p}}\right][\mathrm{DEHP}]$ lubricating greases.

Figure 7 displays the SEM images of the wear scars lubricated with the lubricating greases. The wear scar lubricated with the PAO 10 lubricating grease is characterized by deep furrows and spikes, indicating that adhesive wear and plastic deformation were the major wear forms. However, the wear scars lubricated with the $\left[\mathrm{P}_{88814}\right][\mathrm{DEHP}]$ and $\left[\mathrm{P}_{888 \mathrm{p}}\right][\mathrm{DEHP}]$ lubricating greases were much smoother with shallow furrows, revealing their better antiwear properties. The furrows in the wear scar lubricated with ZDDP and $\left[\mathrm{P}_{88814}\right][\mathrm{AOT}]$ lubricating grease are slightly deeper than those on the wear scars lubricated with the $\left[\mathrm{P}_{88814}\right][\mathrm{DEHP}]$ and $\left[\mathrm{P}_{888 \mathrm{p}}\right][\mathrm{DEHP}]$ lubricating greases.
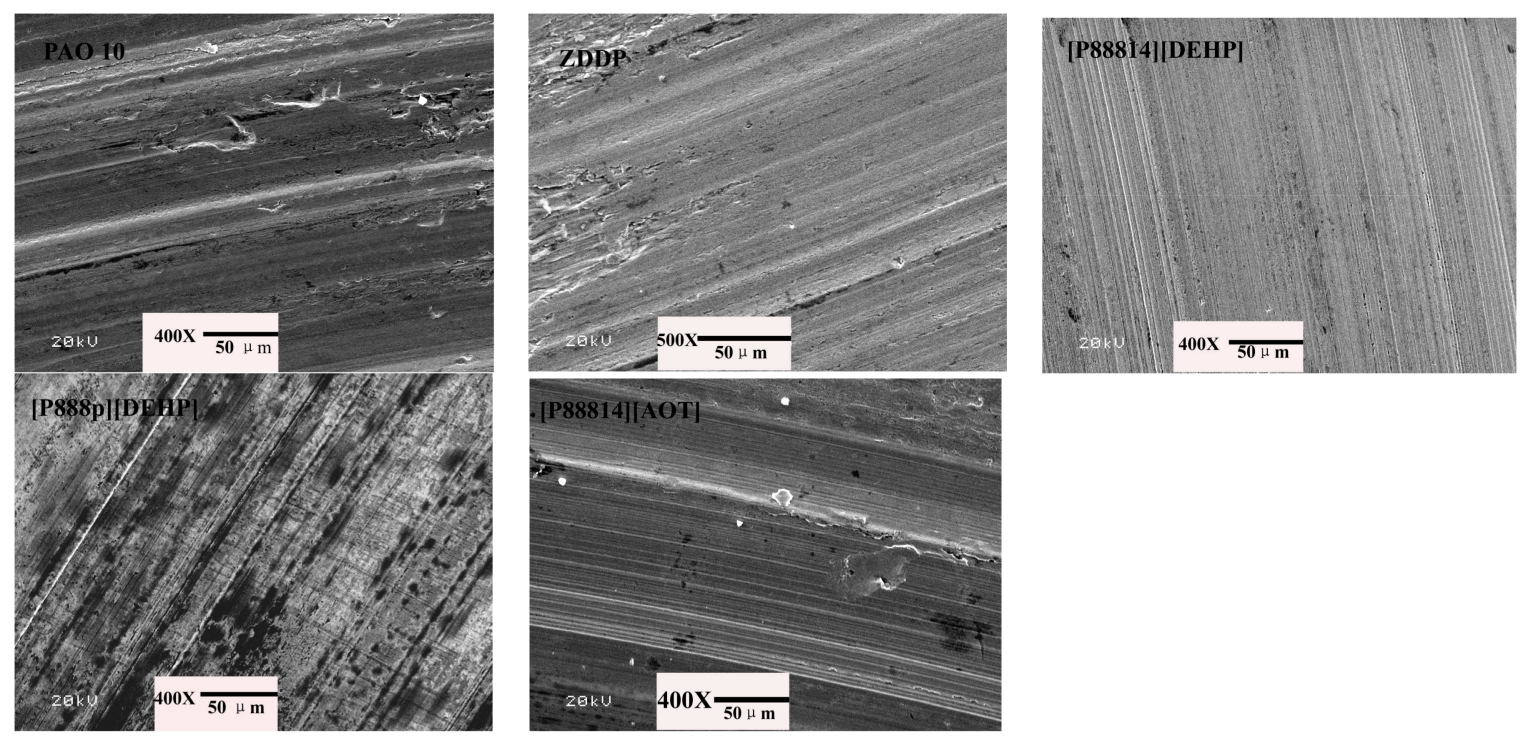

Figure 7. SEM morphologies of wear scars lubricated with the lubricating greases.

Figure 8 shows the EDS spectra of the worn surfaces lubricated with the lubricating greases and Table 3 shows the element content. The signatures of phosphorus and sulfur appeared on the EDS spectra of the worn surfaces lubricated with ILs lubricating greases, revealing the formation of a tribochemical thin film composed of ionic liquids and/or a tribochemical product of the ionic liquids, whereas the PAO 10 grease-lubricated worn surface showed no signals for phosphorus or sulfur [18]. To further investigate the composition of the tribochemical film, the element composition of the tribochemical film was analyzed by XPS.

Table 3. The element content of the worn surface lubricated with different lubricating greases.

\begin{tabular}{cccccc}
\hline & C (At\%) & O (At\%) & P (At\%) & S (At\%) & Fe (At\%) \\
\hline PAO 10 & 8.07 & 15.83 & - & - & 58.46 \\
ZDDP & 30.96 & 11.09 & 0.09 & - & 57.81 \\
[P88814][DEHP] & 20.18 & 14.68 & 0.56 & - & 64.58 \\
[P888p][DEHP] & 13.01 & 9.37 & 1.25 & - & 76.37 \\
[P88814][AOT] & 23.37 & 7.49 & 0.17 & 1.35 & 67.61 \\
\hline
\end{tabular}



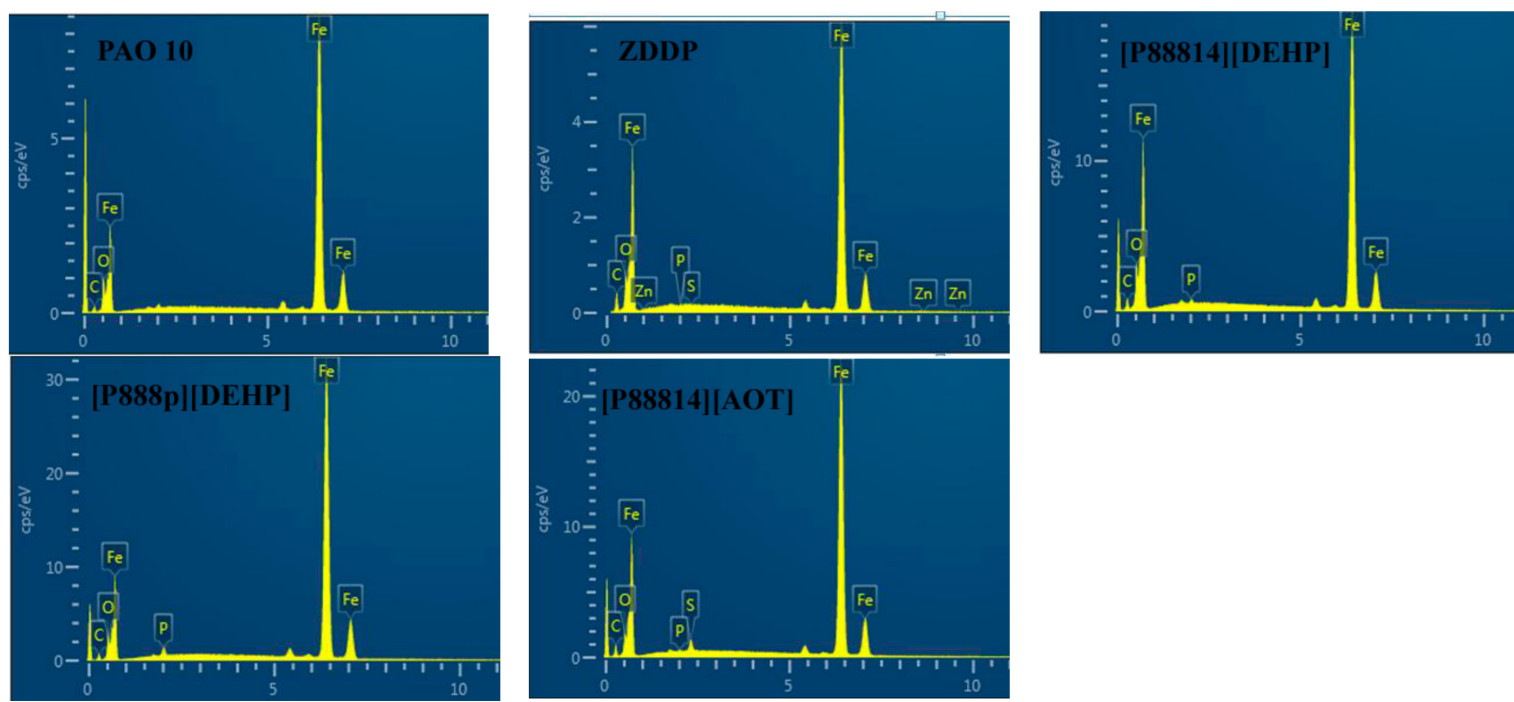

Figure 8. EDS spectra of the worn surfaces lubricated with the lubricating greases.

Figure 9 shows XPS spectra of the lubricating grease and the worn surface lubricated with the corresponding lubricating grease. All of the worn surfaces show an O1s peak at $530 \mathrm{eV}$ combined with Fe2p peaks, indicating the formation of ferric oxide. Besides the ferric oxide, the XPS spectra indicate that the composition of the tribochemical film differs among the different lubricating greases. The worn surface lubricated with the $\left[\mathrm{P}_{88814}\right][\mathrm{DEHP}]$ and $\left[\mathrm{P}_{888 \mathrm{p}}\right][\mathrm{DEHP}]$ lubricating greases show an O1s peak at $531.3 \mathrm{eV}$ and a P2p peak at $133.7 \mathrm{eV}$. According to the literature, the two peaks correspond to $\mathrm{Fe}\left[\mathrm{PO}_{4}\right][19]$. The worn surface lubricated with the $\left[\mathrm{P}_{88814}\right][\mathrm{AOT}]$ lubricating grease shows a new peak of $\mathrm{S} 2 \mathrm{p}$ at $161.6 \mathrm{eV}$, assigned to $\mathrm{FeS}_{2}$. The above results reveal that the ionic liquids react with the substrate surface and form a tribochemical film to reduce friction and wear.

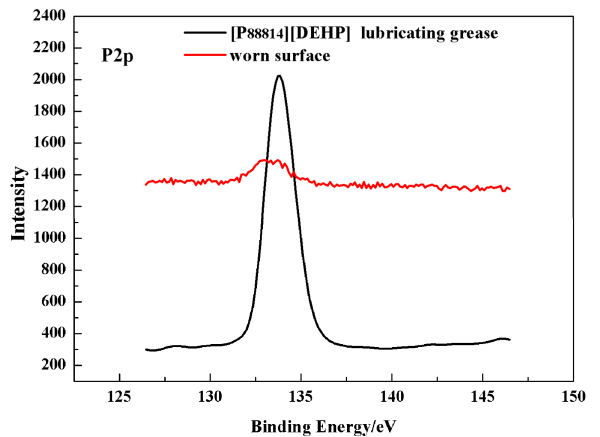

(a)

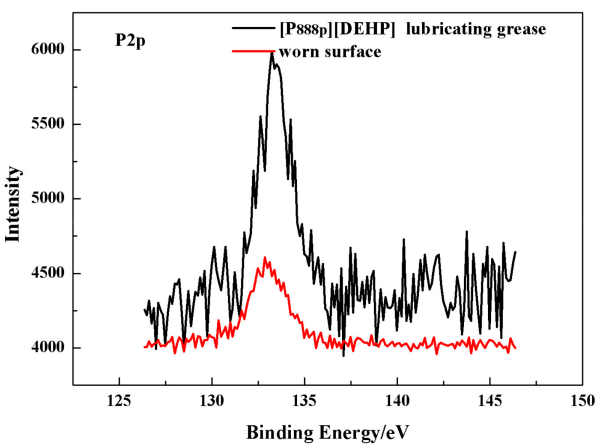

(c)

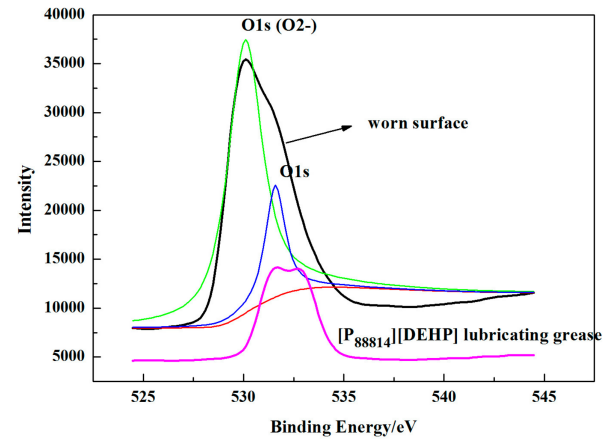

(b)

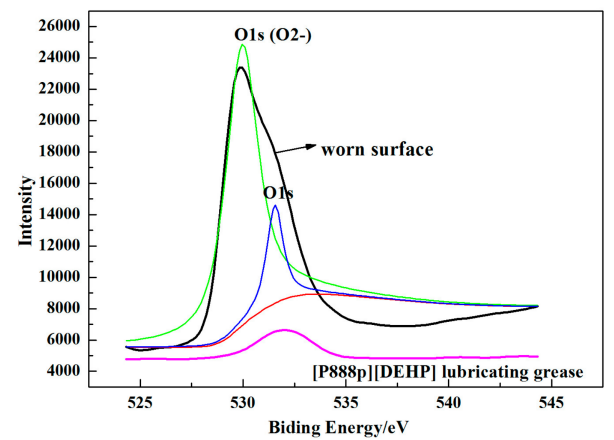

(d)

Figure 9. Cont. 


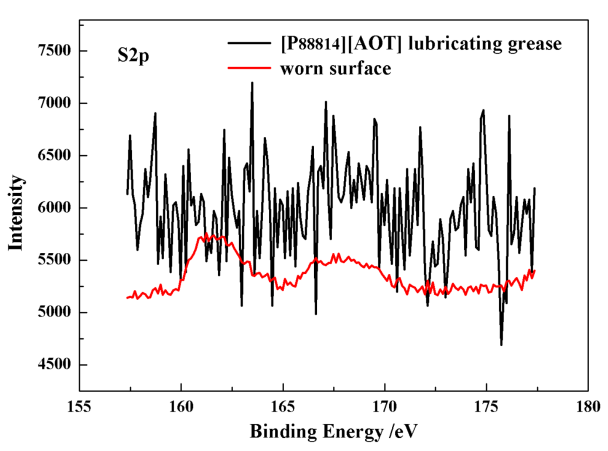

(e)

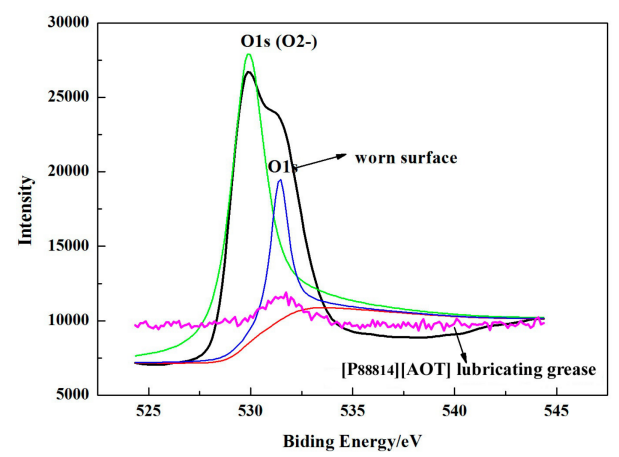

(f)

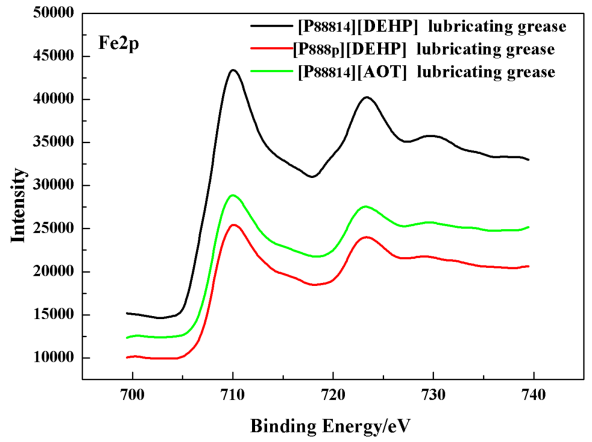

(g)

Figure 9. XPS spectra of the lubricating greases and worn surfaces lubricated with lubricating greases (a) P2p of $\left[\mathrm{P}_{88814}\right][\mathrm{DEHP}]$ lubricating grease and worn surface, $(\mathbf{b}) \mathrm{O} 1 \mathrm{~s}$ of $\left[\mathrm{P}_{88814}\right][\mathrm{DEHP}]$ lubricating grease and worn surface, $(\mathbf{c})\left[\mathrm{P}_{888 \mathrm{p}}\right][\mathrm{DEHP}]$ lubricating grease and worn surface, (d) O1s of $\left[\mathrm{P}_{888 \mathrm{p}}\right][\mathrm{DEHP}]$ lubricating grease and worn surface, (e) S2p of [ $\left.\mathrm{P}_{88814}\right]$ [AOT]lubricating grease and worn surface, $(\mathbf{f}) \mathrm{O} 1$ s of $\left[\mathrm{P}_{88814}\right][\mathrm{AOT}]$ lubricating grease and worn surface, $(\mathrm{g}) \mathrm{Fe} 2 \mathrm{p}$ of worn surface.

\section{Conclusions}

Three phosphonium ILs, $\left[\mathrm{P}_{88814}\right][\mathrm{DEHP}],\left[\mathrm{P}_{888 \mathrm{p}}\right][\mathrm{DEHP}]$, and $\left[\mathrm{P}_{88814}\right][\mathrm{AOT}]$, were synthesized and their decomposition temperatures, densities, and kinematic viscosities were then characterized. The ILs were dissolved in PAO 10 at a concentration of $5 \mathrm{wt} \%$ to form oil-IL blends. The oil-IL blends were used as base stock to prepare lithium greases. The effects of ILs on the physical, rheological, and tribological properties of lithium lubricating grease were investigated. The results are as follows:

(1) The $\left[\mathrm{P}_{88814}\right][\mathrm{DEHP}]$ grease showed a higher dropping point than the PAO 10 grease, and the dropping point of the $\left[\mathrm{P}_{888 \mathrm{p}}\right][\mathrm{DEHP}]$ grease and the $\left[\mathrm{P}_{88814}\right][\mathrm{AOT}]$ grease is lower than that of the PAO 10 grease. All of the lubricating greases are noncorrosive to copper.

(2) Compared with the PAO 10 grease, the values of the linear viscoelasticity modulus of the $\left[\mathrm{P}_{88814}\right][\mathrm{DEHP}]$ and $\left[\mathrm{P}_{88814}\right][\mathrm{AOT}]$ greases decreased. However, the same values of the linear viscoelastic functions were found for the $\left[\mathrm{P}_{888 \mathrm{p}}\right][\mathrm{DEHP}]$ grease.

(3) The ILs were found to be effective lubricant additives for improving the friction-reducing and antiwear properties and the maximum non-seizure load ( $P_{\mathrm{B}}$ values) of PAO 10 lithium lubricating grease. A surface analysis showed that a tribochemical film was generated from the ILs to reduce friction and wear.

Acknowledgments: This work is funded by the National Natural Science Foundation of China (51465049), the National First-rate Discipline Construction Project of Ningxia (CET-JX-2017A01), and Major Innovation Projects for Building First-class Universities in China's Western Region (ZKZD2017003).

Author Contributions: In this study, Zeyun Wang conceived and designed the experiments; Zeyun Wang and Jun Chang performed the experiments; Chao Cai analyzed the data; and Zeyun Wang wrote the paper.

Conflicts of Interest: The authors declare no conflict of interest. 


\section{References}

1. Martín-Alfonso, J.E.; Valencia, C.; Sánchez, M.C.; Franco, J.M.; Gallegos, C. Development of new lubricating grease formulations using recycled LDPE as rheology modifier additive. Eur. Polym. J. 2007, 43, 139-149. [CrossRef]

2. Mas, R.; Magnin, A. Rheology of colloidal suspensions-case of lubricating greases. J. Rheol. 1994, 38, 889-908. [CrossRef]

3. Yeong, S.K.; Luckham, P.F.; Tadros, T.F. Steady flow and viscoelastic properties of lubricating grease containing various thickener concentrations. J. Colloid Interface Sci. 2004, 274, 285-293. [CrossRef] [PubMed]

4. Sánchez, M.C.; Franco, J.M.; Valencia, C.; Gallegos, C.; Urquiola, F.; Urchegui, R. Atomic force microscopy and thermo-rheological characterisation of lubricating greases. Tribol. Lett. 2011, 41, 463-470. [CrossRef]

5. Fan, M.J.; Yang, D.S.; Wang, X.L.; Liu, W.M.; Fu, H.Z. DOSS-based QAILs: As both neat lubricants and lubricant additives with excellent tribological properties and good detergency. Ind. Eng. Chem. Res. 2014, 53, 17952-17960. [CrossRef]

6. Ye, C.F.; Liu, W.M.; Chen, Y.X.; Yu, L.G. Room-temperature ionic liquids: A novel versatile lubricant. Chem. Commun. 2001, 21, 2244-2245. [CrossRef]

7. Otero, I.; Lópezm, E.R.; Reichelt, M.; Villanueva, M.; Salgado, J.; Fernández, J. Ionic liquids based on phosphonium cations as neat lubricants or lubricant additives for a steel/steel contact. ACS Appl. Mat. Interfaces 2014, 6, 13115-13128. [CrossRef] [PubMed]

8. Huang, G.W.; Yu, Q.L.; Cai, M.R.; Zhou, F.; Liu, W.M. Investigation of the lubricity and antiwear behavior of guanidinium ionic liquids at high temperature. Tribol. Int. 2017, 114, 65-76. [CrossRef]

9. Gusain, R.; Dhingra, S.; Khatr, O.P. Fatty-acid-constituted halogen-free ionic liquids as renewable, environmentally friendly, and high-performance lubricant additives. Ind. Eng. Chem. Res. 2016, 55, 856-865. [CrossRef]

10. Fan, M.J.; Liang, Y.M.; Zhou, F.; Liu, W.M. Dramatically improved friction reduction and wear resistance by in situ formed ionic liquids. RSC Adv. 2012, 2, 6824-6830. [CrossRef]

11. Mozes, R.; Cooper, P.K.; Atkin, R.; Li, H. Ionic Liquids as Grease Base Liquids. Lubricants 2017, 5, 31. [CrossRef]

12. Anand, M.; Hadfield, M.; Viesca, J.L.; Thomas, B.; Battez, A.H.; Austen, S. Ionic liquids as tribological performance improving additive for in-service and used fully-formulated diesel engine lubricants. Wear 2015, 334, 67-74. [CrossRef]

13. Qu, J.; Bansal, D.G.; Yu, B.; Howe, J.Y.; Luo, H. Antiwear performance and mechanism of an oil-miscible ionic liquid as a lubricant additive. ACS Appl. Mat. Interface 2012, 4, 997-1002. [CrossRef] [PubMed]

14. Westerholt, A.; Weschta, M.; Bösmann, A.; Tremmel, S.; Korth, Y.; Wolf, M.; Schlücker, E.; Wehrum, N.; Lennert, A.; Uerdingen, M.; et al. Halide-free synthesis and tribological performance of oil-miscible ammonium and phosphonium-based Ionic Liquids. ACS Sustain. Chem. Eng. 2015, 3, 797-808. [CrossRef]

15. Cai, M.R.; Zhao, Z.; Liang, Y.M.; Zhou, F.; Liu, W.M. Alkyl imidazolium ionic liquids as friction reduction and anti-wear additive in polyurea grease for steel/steel contacts. Tribol. Lett. 2010, 40, 215-224. [CrossRef]

16. Wang, Z.Y.; Xia, Y.Q.; Liu, Z.L. Comparative study of the tribological properties of ionic liquids as additives of the attapulgite and bentone greases. Lubr.Sci. 2012, 24, 174-187. [CrossRef]

17. Huang, G.W.; Yu, Q.L.; Ma, Z.F.; Cai, M.R.; Liu, W.M. Probing the lubricating mechanism of oil-soluble ionic liquids additives. Tribol. Int. 2017, 107, 152-162. [CrossRef]

18. Gusain, R.; Gupta, P.; Saran, S.; Khatri, O.P. Halogen-Free Bis(imidazolium)/bis(ammonium)-di[bis(salicylato) borate] ionic liquids as energy-efficient and environmentally friendly lubricant additives. ACS Appl. Mat. Interface 2014, 6, 15318-15328. [CrossRef] [PubMed]

19. Zhang, L.; Feng, D.; Xu, B. Tribological characteristics of alkylimidazolium diethyl phosphates ionic liquids as lubricants for steel-steel. Tribol. Lett. 2009, 34, 95-101. [CrossRef]

(C) 2018 by the authors. Licensee MDPI, Basel, Switzerland. This article is an open access article distributed under the terms and conditions of the Creative Commons Attribution (CC BY) license (http:/ / creativecommons.org/licenses/by/4.0/). 